\title{
The Learning Organisation: A School's Journey Towards Critical and Creative Thinking
}

Kala S. Retna

Victoria University of Wellington, New Zealand

Senge's learning organisation (LO) concept was introduced in many Singaporean schools to promote a learning culture. The implementation of the LO concept in organisations was in response to Singapore's call for all schools to be 'thinking schools' and the Singapore Ministry of Education's pronouncement that the foremost prerequisite of a thinking school is that it must be a learning organisation. This paper describes a qualitative study that was conducted in a secondary school that practiced the LO concept. The research was undertaken with a key focus on understanding how the implementation of the LO concept has enhanced open communication, a learning culture and critical and creative thinking. The research also identifies constraints, especially cultural ones. The findings suggest that LO concept produced significant progress towards an environment of a shared learning culture, effective communication and good working relationships among the staff. It has also helped to increase the level of awareness and the importance of critical and creative thinking in the school. However, strategies and activities used to promote critical and creative thinking were used sparingly so as not to undermine the 'academic excellence' that is important to the school's reputation as a 'good school.' Also, the curriculum structure and compulsory coverage of syllabus for examination as well as general cultural inhibitions were some of the factors that limited the growth of critical and creative thinking in the school. The paper concludes with implications for both academics and practitioners within organisations.

The twenty first century demands that everyone and every organisation learn in order to cope with the changes that are rapidly taking place in its environment. Globalisation, changing technology and uncertainty are some of the factors that are challenging organisations in the new century to keep pace with the speed of change (Marquardt, 2002; Wang \& Ahmed, 2003). According to some authors, the greatest, or indeed the only, source of competitive advantage for any organisation is its ability to learn (De Geus, 1988; Edmonson \& Moingeon, 1996; Finger \& Brand, 2003; Senge, 1990). The importance of learning and the relevance of developing the learning capacity of individuals and organisations was emphasised with the launch of the 'Fifth Discipline' by management guru Peter Senge in the 1990s. Since then, the Learning Organisation (LO) concept has been 
widely seen as offering one solution to the problems faced by organisations in an environment of increased globalisation, competition and change (Garratt, 1987; Pedler \& Aspinwall, 1998; Stewart, 2001). The LO concept is generating an extensive body of literature with many competing views of its importance. The proliferation of articles and conferences about the idea of a Learning Organisation attests to LO's popularity among practitioners and academics (Elena, Joep \& Susanne, 2003; Marquardt, 2002). Though the LO concept has antecedent in learning theories (Jackson, 2001; Watkins \& Marsick, 1994) the literature acknowledges Peter Senge for bringing the learning organisation into the mainstream of business thinking (Marquardt, 2002). Today, the concept of LO has carved itself a viable and sustainable niche in the management studies literature.

Despite the popularity of the notion of a Learning Organisation, many authors suggest that it is difficult to define a Learning Organisation. Some authors have even suggested that it might be impossible to describe what a learning organisation would look like (Marquardt \& Reynolds, 1994; Pedler \& Aspinwall, 1998; Stewart, 2001; Watkins \& Marsick, 1994). According to Senge (1990) a Learning Organisation is an "organisation where people continually expand their capacity to create the results they truly desire, where new expansive patterns of thinking are nurtured, where collective aspiration is set free, and where people are continually learning how to learn together" (Senge, 1990, p.14). Senge constructs his concept of a learning organisation using five inter-dependent disciplines. When these are implemented in unison, he argues, organisational learning can be achieved. These disciplines have evolved from Senge's belief that an organisation should focus its attention to the conditions that motivate people to do great things for themselves and for their organisations. The five disciplines are the result of Senge's (1990) humanistic view of organisational change. He states that for there to be innovation in human behaviour, the components of his principles need to be seen as 'disciplines.' He emphasized that practising it is not just about achieving organisational performance but also concerns having a personal stake in shaping the organisation's character. Also, Senge's principles of learning were viewed as a means of reinventing schools to facilitate critical and creative thinking skills among teachers and students. His publication 'Schools That Learn' (2001) was highly regarded as a useful handbook to create a new dimension in learning.

Senge's five disciplines are briefly presented:

Systems Thinking focuses on the organisation as a system, so that everyone in the organisation learns to see it as an interrelated whole. It helps to clarify assumptions and actions and see if they are systemically 'flawed.'

Personal Mastery drives people to achieve results that matter to them. It is a matter of commitment to one's own learning. This discipline allows members of the organisation to clarify their personal vision.

Mental Model refers to one's image of reality, a conceptual structure that gives meaning to what we perceive and drives our understanding of our world and ourselves. This can be the force for acceptance of or resistance to progress and change in organisations.

Team Learning forms the foundation for social relationships through dialogue. It allows members to suspend assumptions and enter into genuine 'thinking together.' This discipline aligns a group of team workers to create the desired outcomes (Senge, 1990).

Shared Vision involves skills of unearthing shared 'pictures of the future' that foster genuine commitment by all organisational members. Shared vision is a powerful discipline as it is built on top of a shared mental model; it adds purpose and inspiration to a view of reality (Senge, 1990).

\section{LO, CRITICALAND CREATIVE THINKING IN THE SINGAPORE CONTEXT}

Singapore is the smallest state in South-East Asia, with no hinterland or other natural resources. 
Its only assets are its people and its strategic geographical location. However, despite his disadvantages, Singapore has developed into a very prosperous and dynamic nation (Harley \& Low, 1998). With its exceptional social and economic revolution over the last three decades, Singapore today belongs to the First world and is envied by many in the Third World countries (Vasil, 2000).

Since its independence in 1965, Singapore's government has undertaken phases (Yeo, 2006) to evolve into its current state of success. Over the three decades, Singapore managed well with its strategic interventions to solve unemployment (work phase), labour shortage (skill phase), productivity of labour (productivity of labour), and workforce quality (quality phase). To cope with the demands of advanced globalisation, Singapore emphasised on enhancing its learning capacity as a nation (learning phase).

While Singapore has been very successful in 'catching up' with developed countries, it faces the need to develop creative and critical thinking. 'Catching up' is largely a matter of imitating, but to function as a developed country, especially in the $21^{\text {st }}$ century, creative, critical, and innovating thinking is essential. In 1997, the vision and slogan “Thinking Schools, Learning Nation" (TSLN) was launched by then Prime Minister of Singapore, Goh Chok Tong, in an attempt to transform the nation into a "total learning environment, including students, parents, workers, companies, community organisation and the government (Goh, 1997, p1). The focus of TSLN was to develop all students into active learners with creative and critical thinking culture within the schools (Tan \& Gopinathan, 2000, p.7). He further stated that to fulfill the vision of TSLN, "Our schools and tertiary institutions must become learning organizations" (Goh, 1997, p.1).

One of the initiatives in promoting a learning culture, Singapore launched its 'Learning Festival' (Manpower News, 2000) that was attended by more than 1,000 government officers. Senge was the Distinguished Speaker for the launch whereby he advocated his LO concepts as a tool to achieve a learning environment in Singapore. Subsequent to the launch of the Singapore's Learning Festival, several Ministers have quoted Senge and his LO concept in their speeches that denoted the importance given to the LO concept at a national level (e.g. Goh, 1997). Since then, many organizations have been engaging LO consultants to train their employees to enhance learning capabilities (Ng, 2005). Also, increasingly, Senge's associates have been invited to provide courses/ training that prescribed a variety of models, tools and techniques to Singaporean organisations.

One of the major thrusts of TSNL is the emphasis on critical and creative thinking. Several initiatives have been put into action by the Ministry of Education to promote creativity in schools (Tan \& Gopinathan, 2000). One of the strategies for schools to promote a thinking culture was to include the teaching of critical and creative thinking skills as part of the school curriculum. Following this move, the crucial role played by the teachers in promoting creativity among students received extensive publicity through speeches made by ministers, and magazines and documents from the Ministry of Education. As teachers are the main change agents in schools (Cropley, 1997), they were encouraged to attend workshops and seminars related to critical and creative thinking skills. Senge's LO principles were in many ways perceived to be tools to develop people to be innovative and enterprising. The five principles of LO were regarded as the foundation for school-wide innovation ( $\mathrm{Ng}, 2005)$. Senge's book 'Schools that learn' was popular and a revered resource among teaching staff in facilitating creativity and innovation in Singapore schools. The LO concept is seen by schools and organisations as a method to produce 'active learners with creative and critical thinking.' However, the problem is not solved so easily because Singapore culture, especially with its dominant Confucian roots, is in many ways at odds with the LO concept and with creative and critical thinking. The tension between these two is what the research has explored. 


\section{METHOD}

A qualitative case study methodology was used in this research. Methodological triangulation combined face to face interviews with staff, participant observation as well as scrutiny of organisation documents, records, physical artifacts, and other stories. This was used for data collection. The research was conducted in a school in Singapore that has adopted the learning organisation concept. The schools' LO journey began in the year 2003 with the Principal and senior teachers attending training by LO consultants. Subsequently, every member of the school participated in the visioning process whereby the vision and mission statements were created using five disciplines and the TSLN as a guide. As a follow-up, several processes such as open door policy, flat communication structure, peer learning and evaluation, coaching, reflective practices and on-going professional development were put in place. All these processes were implemented to facilitate a learning and innovative environment in the school. At the time of research, about three years after its implementation, the school claimed to have entered a new phase in education that promotes individual and organisational learning. To maintain confidentiality, the pseudonym Critical Thinking School (CTS) is used throughout this case study.

Post-positivism is the theoretical position adopted in this research. It offers a potentially fruitful theoretical perspective within which to frame qualitative research studies (Crotty, 1998). Postpositivism allows a deeper look into organisational events and activities and focuses on how organisational members engage in these activities and make sense of them (Crotty, 1998). It suggests that respondents' way of making sense of the world is as valid and worthy of respect as any other (Creswell, 1998). Hence, the issue is viewed from a critical realist perspective (Denzin \& Lincoln, 2003). The critical realist asserts that reality is that which is formed by the individuals involved in the research, thus resulting in multiple intangible mental constructions. The form and content of reality is dependent on the individual or the group forming these constructions. Post-positivism emphasizes the hold that culture has on us. In other words, it shapes the way in which we see things and view the world. The research adopts the post-positivist paradigm with the view that the LO concept is an interactive process between a group of individuals and their environment; the focus is on social interaction.

Consistent with qualitative research, I used interview as a method to collect information (Smith, Thorpe \& Lowe, 1997, p.72). Interviews lasting for about 60 to 90 minutes were conducted with 15 teaching staff on an individual basis. An interview guide was derived from the literature to gather information about their opinions on the principles of learning organisation, and creative and critical thinking. The interview guide focused on three key issues (See Appendix A for examples of questions in the interview guide). First, they were asked about how the implementation of LO has impacted their learning culture in the school. These questions included: 'Why is it important for schools to learn? What changes have taken place in terms of learning and teaching in the school? Second, these were followed by questions about their experiences and opinions. Questions included: 'What has been achieved in relation to the LO implementation? The questions focused on finding out about changes in communication processes and work relationships among staff. Finally, the participants were asked as to the extent the implementation of the LO concept enhanced the aspects of critical and creative thinking in the school's learning environment. All the three key issues also focused on identifying cultural constraints.

Participant observation supplements direct faceto-face interviews. In this research, participant observation ranged from informal discussions with students to attending three formal meetings: head of departments, subject specialists, and teachers' monthly forum. During these meetings, important observations were made, such as participants' interaction in formal and informal contexts, people's emotions and feelings as they described their experiences of LO concept, and their journey towards enhancing creative and critical thinking skills. 
The analysis of documentary and administrative sources is one of the strategies used in qualitative research. Cassell and Symon (1994) claimed that organisational documentation can illuminate many aspects of organisational life. I had access to newsletters, brochures and organisational documents and these documents were read and analysed in relation to the interviews. These documents provided background information about the organisation and helped to augment evidence from the other sources such as interviews and observations. These were used in the triangulation process to conform organisational events and practices.

The data analysis procedure followed Constas' (1992) category process development. This approach is based on combining perspectives from the literature and the study. An example of the key categories and components of the categorization are shown in Tables 1 and 2. I used the LO principles and the three dimensions of national culture as the main categories for analysis.

The categorisation process is described according to three procedural elements: origination, verification, and nomination. The origination component explains where the authorities for creating categories reside. In the origination component, I used three sources of origination: participants, literature and interpretation. For example, the origination of category 1 (systems thinking) came from the literature, while the origination of category 11 (hierarchical barrier) came from the participants and the interpretive process.

The verification component describes the strategies used to justify a given category. This can be carried out by two sources: rational and referential. In this analysis, the verification component was applied in two ways. Rational verification was accomplished by demonstrating

Table 1.

Documentational Table for Key Categories

\begin{tabular}{|c|c|c|}
\hline LO Principles & National Culture & Practices that affect LO principles \\
\hline $\begin{array}{l}\text { 1. Systems Thinking } \\
\text { 2. Personal Mastery } \\
\text { 3. Team Learning } \\
\text { 4. Mental Models } \\
\text { 5. Shared Vision }\end{array}$ & $\begin{array}{l}\text { 6. Collectivism } \\
\text { 7. High power Distance } \\
\text { 8. Confucianism }\end{array}$ & $\begin{array}{l}\text { 9. Learning to unlearn } \\
\text { 10. Directed Training for } \\
\text { Organisational Development } \\
\text { 11. Hierarchical Barrier } \\
\text { 12. Dialogue vs Discussion } \\
\text { 13. Training vs Learning } \\
\text { 14. Compliant attitude } \\
\text { 15. Attitude towards critical/creative } \\
\text { thinking } \\
\text { 16. Bureaucratic dysfunction } \\
\text { 17. Respect for authority } \\
\text { 18. In-group interest above self } \\
\text { 19. Power Inequality } \\
\text { 20. Acceptance of rules/direction } \\
\text { from organisation/government } \\
\text { 21. Teamwork vs. Team Learning } \\
\text { 22. Traditional learning style } \\
\text { 23. Examination orientation } \\
\text { 24. Meritocratic education system }\end{array}$ \\
\hline
\end{tabular}


Table 2.

Documentational Table for the development of categories.

\begin{tabular}{|c|c|c|c|}
\hline \multirow{2}{*}{$\begin{array}{l}\text { Component of } \\
\text { Categorisation }\end{array}$} & \multicolumn{3}{|c|}{ Temporal Designation } \\
\hline & Priori & A Posteriori & Iterative \\
\hline $\begin{array}{l}\text { Origination } \\
\text { Where does the } \\
\text { authority for creating } \\
\text { categories reside? }\end{array}$ & & & \\
\hline Participants & & $\begin{array}{l}9,10,11,12,13,14, \\
15,16,17,18,20,21, \\
22,23,24\end{array}$ & \\
\hline Literature & $\begin{array}{l}1,2,3,4,5,6,7,8,12 \\
13,19,20,22,23,24\end{array}$ & & $\begin{array}{l}9,11,13,18,19,20, \\
23\end{array}$ \\
\hline Interpretive & & $\begin{array}{l}9,10,12,13,14,22 \\
24\end{array}$ & $11,12,16$ \\
\hline $\begin{array}{l}\text { Verification On what } \\
\text { grounds can one justify } \\
\text { a given category? }\end{array}$ & & & \\
\hline Rational & $\begin{array}{l}9,11,12,15,17,20 \\
23\end{array}$ & $\begin{array}{l}1,2,3,4,5,6,7,8,9 \\
10\end{array}$ & \\
\hline Referential & $\begin{array}{l}1,2,3,4,5,6,7,8,13 \\
16,20,23,24\end{array}$ & & \\
\hline $\begin{array}{l}\text { NominationWhat is the } \\
\text { source of the name used } \\
\text { to describe a category? }\end{array}$ & & & \\
\hline Participants & & & $\begin{array}{l}10,11,13,15,21,22, \\
23,24,\end{array}$ \\
\hline Literature & $\begin{array}{l}1,2,3,4,5,6,7,8,12 \\
13,19,20,22,23\end{array}$ & & \\
\hline Interpretive & & $9,10,11,12,15,16$ & \\
\hline
\end{tabular}


logic and reasoning while the referential verification was achieved using theoretical arguments. For example, category 1 (systems thinking) is referential based on theory, while category 11 (hierarchical barrier) was based on rational verification.

\section{FINDINGS}

\section{Learning Revisited}

Several authors have accepted the concept of learning as a necessity for survival and the foundation for a sustainable competitive advantage (Epstein \& Roy, 1997; Fiol \& Lyles, 1985; Garratt, 1987; Grieves, 2000; Kiechel, 1990; Marquardt, 2002; Senge, 1990). The discussions with research participants on the need for individuals and organisations to learn were interesting as their explanations carried a strong affinity for a learning culture. Being a teaching institution, teachers considered learning as an enjoyable aspect of their job and considered the ability to learn and unlearn as one of the critical issues for them and the students in CTS. Most participants emphasised that the movement to LO has brought about a shift in their thinking about their learning and teaching and was beneficial for them and their students to expand their capacity for performing well beyond their limits. For example, teachers were encouraged to reflect on their teaching practices on a weekly basis. A specific time is allocated every week for 'reflection' in the teaching schedule and also to share their reflective practices with other teachers in the school. Reflection, a core element of LO, allows people to think over things and make sense of own and others' experiences (Senge, Kleiner, Roberts, Ross \& Smith,1994). Reflection is an important aspect in self-development and teaching (Zepke, Nugent \& Leach, 2003). All the teachers claimed that 'scheduled reflection time' not only helped them to adjust their teaching material and goals accordingly, but also gave them 'new' energy and challenges in their day-to-day class management.
A paradigm shift can be seen in their concept of learning, as explained by a teacher:

The LO concept slowly changed our thinking. For me I realised that I am not only a teacher, but a learner too. Learning everyday from other teachers and from my students are also very important to me now. This helps me to reflect and change my old habits of teaching and thinking.

The above quote shows the importance of individual learning and how it has helped to change the teaching goals and adjust them accordingly. This is in line with the concept of double-loop learning that involves challenging the fundamental rules and norms underlying action and behaviour and changing them if necessary, resulting in skill development and insight, which generally have long term effects and consequences for the entire organisation (Arygris, 1999; Senge, 1990). Other responses from the interviews also suggest that teachers in CTS valued learning and consciously recognized it as specifically important for those in the teaching profession to learn continuously and collectively. The importance of learning for teachers is illustrated by this example:

In the past, I believed that only students learn from teachers. But I am wrong. Through the LO I understand that teaching and learning cannot be separated. A teacher has to always learn to create new ideas and things for the school and students. Though I have been a teacher for so many years, only now I think I am truly a good teacher.

Many other responses characterise the school as one where learning is identified as important for professional and personal development. Some of the explanations during the interviews indicate that the teachers understand and interpret the kind of learning prescribed by Senge (1990), which was brought about through the implementation of the LO concept in the school. It is evident through the interviews that the teachers were committed to their own learning which reflects the discipline of 
personal mastery, which accordingly to Senge (1990) is the cornerstone of the learning organisation. However, despite the positive experiences with the practice of personal mastery, some teachers in the sample hinted that there are a few staff members and students who are still holding on to the traditional way of learning. I quote a senior teacher:

I think the learning here is very odd for old timers. I feel personally, most Singaporeans are the type that they prefer to work or study alone. And also, in the past, we teachers don't have to spend so much of time on learning or sharing our knowledge with other teachers. It is a bit difficult to change, but I am trying.

The above quote explains some of the cultural inhibitions that are experienced by teachers in the school. Despite the cultural constraints, most of the participants strongly acknowledged that learning must be valued, shared and most importantly, they claimed that teachers who learn are those who will be able to enhance students' knowledge in and beyond the classroom. Senge (1990, p236) asserted "organisations learn only through individuals who learn, but without it no organisational learning occurs". The findings in the case organisation aligns with Senge's LO concept which advocates that all organisations must continuously transform through the learning and reflective activities of all its employees (Senge, 1990).

\section{Greater use of Dialogue}

Dialogue is a creative, open-ended activity of a group thinking together (Senge, 1990). In dialogue, people suspend their positions and probe others for their reasoning to rediscover new possibilities (Isaacs, 1999). For teams in a learning organisation, what counts most is tapping the quality of ideas that are available only to teams, composed of members who practice a way of working together that gives access to the best of their collective, creative thinking. This is the primary benefit of dialogue, according to Senge (1990). This is further emphasised by Isaacs (1999) who claimed that "the discipline of dialogue is central to organisational learning because it holds promise as a means for promoting collective thinking and communication. The findings show that CTS has made dialogue a central feature to improve communication and team learning among the staff. The desire to move beyond the traditional way of communicating was confirmed by numerous stories and examples provided by the participants. Most of them admitted that their initial reaction was less than favourable. However, over time they became convinced that the practice of dialogue is an effective tool that has enhanced the quality of communication among staff. A junior teacher expressed:

Initially, I didn't like the idea of dialogue. After participating for some time I think it is a good technique to get people to voice their ideas and thoughts on certain issues. It teaches us to listen patiently to what people say. We solve all our issues through dialogue. It helps us to appreciate and be close with others.

Similarly, a senior teacher explained:

Dialogue sessions help us to listen and understand other people's views. It is amazing to see teachers across all disciplines give multiple perspectives over issues. This type of communication brings people together. In a nutshell, I must say dialogue has improved our communication and our working relationship.

These responses were typical of many participants' view on using dialogue as a way of promoting open communication, solving problems, and learning from each other. The dialogue, which Senge advocates, depends on the courage and ability of individuals to share intuitions and thoughtful musings with the team (Senge, 1990). These elements were evident across the school. 
Although the interviews were overwhelmingly positive about using dialogue in promoting open communication and collective learning, there was some resistance expressed by a few teachers. These teachers felt the need to be extra cautious in their use of words as they did not want to offend their senior teachers or head of departments during the session. These explanations reflect the broader cultural behaviour of the members that shapes values such as respect for senior staff in the hierarchy. The LO concept advocates the practice of dialogue to understand the context of daily interaction and experience and become aware of the processes of thought and feeling that created that experience (Senge, et al, 1994). It opens paths to change and clears space for organisational transformation $(\mathrm{Ng}, 2004)$. Thus, the practice of dialogue is one of the communication tools that enable the school to realize the vision of becoming a learning organisation.

\section{Promoting a trusting culture}

There is consensus among some researchers that trust is an essential element in a learning organisation (Davenport \& Prusak, 1997; Pillai, Schriesheim \& Williams, 1999; Senge, 1990). It forms the foundation for cooperation between individuals and teams. When people trust each other, other means of governance and control can be minimised to a level that is required by the type of work and risks involved. The development of trust is a function of a leader's ability to create the setting with which trust can develop over time (Ng, 2005; Senge, 1990b). Building an environment of complete trust involves all members of the organisation. Both the management and employees alike must be committed to building relationship based on trust (Gardiner \& Whiting, 1997). One of the characteristics of a learning organisation is that it is built upon the competence of trust (Handy, 1995). The interview responses revealed that the work environment and context promoted attitudes, moods and emotions and values underlying trust. The Principal demonstrated significant trust and respect for the employees that endorsed and encouraged open communication and trusting relations. Responses were positive, suggesting that the participants have already moved a considerable distance down the road towards 'trustworthy relationship' in the school, as can be seen from this comment:

All of us in this school have a good knowledge on LO and Human Dynamics. These knowledge and our principal's leadership have made us comfortable in trusting others. I feel safe to discuss about my students, teaching and anything I want to say. I even can talk to Principal if I have a personal problem.

Another teacher compared her experience:

It took me some time before I could trust my HOD or Principal because they are incharge of promotion or pay increase. This is a LO school. We work together very closely and we dialogue a lot. I have the courage to talk to my HOD anything because we don't play each of us out.[don't betray].

Several similar responses indicated that the teachers feel trust as they perceived their working environment and leadership to be liberating rather than constraining. The interview responses had an integrated mix of four characteristics that teachers found intrinsic to a trusting behaviour: open communication, sharing of information, a sense of caring and mutual respect.

The school seemed to have an appropriate organisational structure and good communication systems that promoted good relationships. My discussions with staff during formal and informal meetings seemed to indicate that a climate of trust prevailed in the school. For example, a junior teacher said that she could call her HOD and request for leave or time off without giving any reason because her HOD trusted her very much. However, although the interview data suggested a degree of trust by leader and 
members in the school, some concerns have been noted in some of the responses such as:

I trust my colleagues very much but I am not sure about my HOD and Principal. I don't know how to explain this feelings. I think it is because they are my people above my head [superiors].

The above quote is based on a deep-seated cultural behaviour. This may partly explain why, although the majority of the responses seemed to be positively conclusive of a save working environment, the above participant's comments reflected the type of governance and working relationship in Singapore schools. Employees tend to guard themselves from being too "visible" to superiors, for fear of being judged unfairly.

\section{Embracing Thinking Skills}

Critical and creative thinking are important in all forms of learning as they are considered to be part of the good thinking processes. Critical thinking involves identifying and challenging assumptions, and exploring and imagining alternatives (Brookfield, 1987). Creative thinking is defined as the ability to generate ideas and work that is both novel and useful (Ochse, 1990; Sternberg \& Lubart, 1999). Critical and creative thinking and the learning organisation concept have a common ground: they are based on people and learning that helps to enhance the capacity of critical and creativity skills among people (Senge, 1990). According to Morgan (1993), creativity is a prerequisite for implementing LO. The LO concept facilitates learning that leads to continuous improvement and innovation.

The discussion on what the participants understand about critical and creative thinking reflect a common understanding of the importance of promoting a learning culture where students can move away from the habit of mere mastery of content to one that helps them think critically and creatively. In terms of definitions, none of the participants were able to define or differentiate the concepts of critical and creative thinking. They explained that they did not want to bother much about the theoretical aspects or the precise definitions of these concepts as their intention is to make creativity a way of life in CTS.

A majority of the teachers commented that every student in their class had the capacity and potential of being creative in one or several subjects. They also felt that as teachers they could play an important role in enhancing creativity through classroom activities. The teachers' attitude corresponds to some authors who claim that most teachers and educators strongly believe that every individual has potential to exercise their creative talents (Craft, 2003; Gardner, 1985; Negus \& Pickering, 2004). The research data reveal that the main concern was to move the students away from their traditional style of learning, i.e regurgitation of information from teachers or text books. This was explained by a senior teacher:

Re-producing knowledge from textbooks and getting good grades does not really mean they know the subject well. I can't blame them. I too studied like that in my school. This is to do with our education system. It is good that Singapore now want all of us to think critically. In this school, we are all in for it. We have everything in place to drive the process of creativity.

The findings show that most of the teachers were committed towards supporting their school vision of harnessing creativity among the students, and also to support Singapore's vision of developing individuals into critical and creative thinkers (Goh, 1997). From the pedagogical perspective, it was evident from the interviews and informal discussions that the teachers' thinking about teaching and learning have also changed. Three key explanations were given. First, students should not be regarded as passive learners but as people who can actively construct knowledge basing on their prior experience and knowledge (Piaget, 1972). Second, new learning strategies and activities should be used to promote active learning among students. Finally, a classroom 
environment that encourages creativity among students should be provided.

It is evident from these explanations that the teachers in CTS understand that fostering creativity in their classroom entails going beyond the structured syllabus. This is in line with some authors, for example, Tan (2001) who claims that the process of developing creativity demands more than just achieving the conventional educational objectives. There was a positive indication from the research that the teachers strongly believed that every student was capable of thinking independently if educators provided conditions conducive to developing thinking skills. This is strongly captured in a comment by a junior teacher:

I belief every person can develop thinking skills. I am saying this with $100 \%$ confidence because it is stated in my school vision and we put our mind and heart to let it happen to our students. Our efforts are paying off.

The above quote and other data from the research highlight the heightened awareness of the importance of critical and creative thinking for students and the challenge of teaching that differs from the traditional teacher-student model. All the teachers explicitly expressed that their paradigm shift about thinking skills came about through their understanding of the concept of shared vision and systemic thinking. They emphasized that the shared vision helped them to commit themselves towards the quality of student learning and thinking and systems thinking helped them to see students' learning from a broad perspective. In other words, the teachers in CTS are not only concerned about their students' current needs, but they also understand the importance of developing students to meet future challenges in personal, professional and societal context (Craft, 2003; Goh, 1997). Despite the positive and encouraging responses from the majority of teachers however, a few teachers explained that they encounter some resistance from the students who still prefer specific instructions from teachers on what to learn. They resist the transformation of the self in relation to thinking independently or collectively as a group. Their resistance reflects the Singapore system of education. Some students feel that time is being wasted by thinking critically and they would rather spend more time focusing on the examination syllabus to achieve good grades. Along a similar vein, some teachers acknowledged that they too find it difficult to introduce activities that promote creativity. Two reasons were offered: too time consuming and the need to cover the syllabus for final school examination. There was also some concern as to whether it was really necessary for teachers and students to be overly involved in the process of critical and creative thinking skills. This is captured in the following comment made by a junior teacher:

Time is a big, big problem. We need to cover syllabus and also to make sure that our students get good grades. Critical thinking is good but grades come first. Students' main intention is to get good grades and to get a place in university.

The above quote and other informal discussions reveal some issues that are encountered by some teachers in promoting creativity in CTS, such as, the pressure to prepare students according to curriculum, lack of time during lessons and students' competitive nature. In sum, the findings show that despite some shortcomings, the majority of the teachers were determined to foster critical and creative thinking among their students.

\section{LO and Critical and Creative Thinking}

The teachers were asked what kinds of activities or strategies were used to promote critical and creative thinking in CTS. All the participants in the interviews expressed three strategies: reflection, student-teacher conversation and problem-solving. All these strategies are important components in LO concept in creating a learning mindset (Senge, Cambron-McCabe, Lucas, Smith, Dutton, \& Kleiner, 2001). Some of the teachers explained 
that students respond positively towards these strategies as it gives them an opportunity to reflect on their daily learning tasks, raise questions and critique their peers and teachers during class conversations, and generate a variety of possible ideas and knowledge in problem solving activities. The main core of promoting critical and creative thinking is through reflective learning that helps students to read and write critically after their class activities. Many examples were made available during the interviews on how teachers promote thinking skills in their classroom. Some of the teachers proudly claimed that the integration of these strategies have been successful as the students' passing rate has increased since the implementation of the LO concept. Data from school publications, documentation and artifacts support this claim. For example, the school's newsletter confirmed the $13 \%$ increase in the General Certificate Examination (GCE ' $\mathrm{O}$ ' Level) and the award ceremony and presentation for students who excelled in examinations and creativity projects. The spirit of LO, critical and creative thinking were vividly captured in the school vision, mission and philosophy. The school's notice boards displayed names of student leaders' who headed committees such as Learning Circles, Creative Projects, Learning and Reflection. These notice boards also carried reviews of critical and creative thinking projects by subject specialties. Overall, the research reveals that while the teachers' understanding and use of critical and creative thinking strategies were limited, their understanding of LO principles have created a desirable thinking culture according to Singapore's vision of TSLN.

\section{CONCLUSION}

In this paper I have explored the practice of the LO concept in a secondary school through a qualitative case study. I have demonstrated through this research that there is evidence to indicate that the practice of LO has produced significant progress towards an environment of a shared learning culture, effective communication and good working relationship among staff and has fostered critical and creative thinking among students. There were two issues that are noteworthy in this research. First, there were some concerns about cultural inhibitions with the practice of the LO concept. For example, Singapore's power relations and inequalities are in direct contrast to the LO concept that promotes an egalitarian power-based relationship (Dixon, 1998) between superiors and subordinates. Authoritarian leadership is considered a positive attribute among Singapore employees. This is supported by the findings of Zhang's (1994) study on 200 Singapore school principals that revealed 'authoritative' leadership as one of the key common characteristics displayed by successful principals and this attribute is a cultural characteristic of Singapore. Many studies have concluded that learning is inhibited in traditional bureaucratic structures (Bartlett \& Ghoshal, 1998; Fullan, 1993) and my findings add credence, particularly from a cultural perspective. In spite of the cultural inhibitions the research participants were confident that given a bit more time, they will be able to overcome these constraints. This highlights their critical reflective attitude towards personal mastery and their commitment and support towards the school's vision. Second, though the teachers were constrained by syllabus, time and to a certain extent, a lack of knowledge of creative strategies for nurturing critical and creative thinking, their efforts are note worthy.

In terms of implications for practitioners and academics, the findings show that while the teachers were positive and enthusiastic about fostering critical and creative thinking through the LO concept, the curriculum was not conducive to fully embracing a thinking culture. To harness critical and creative thinking, it is important for schools to redesign curriculum to include methodological principles and to develop competence to engage students in higher-order thinking. Also teachers should be 
trained and made proficient in skills and strategies not merely for teaching their specific subjects but also to develop their students' creativity in general. In closing, further empirical research is suggested in exploring student perception and their understanding of critical and creative thinking.

\section{APPENDIXA}

\section{Interview Schedule}

\section{INTRODUCTORY QUESTIONS}

\section{Your experience with this organisation}

Prompts:

- How long have you been working in the organisation?

- What were you doing prior to joining this organisation?

- Can you describe your job?

\section{LEARNING ORGANISATION CONCEPT}

\section{What does the phrase 'learning} organisation' mean to you personally?

Prompts:

- How important is learning and why?

- Does the organisation have a defined learning agenda?

- Why do organisations have to learn?

- When was LO introduced in your organisation? What happened?

- In your opinion what was achieved? Can you describe or give examples?

- What role does Singapore culture play in all this?

\section{What is your understanding of critical} thinking?

Prompts:

- What excites you about 'critical thinking'? What doesn't?

- Do you identify critical thinking as a valuable lifelong skill for yourself and students? Can you given an example?
- Do students find critical thinking skills useful to them? Can you relate it with classroom examples and learning experiences?

\section{What is the role of team learning in your organisation?}

Prompts:

- Can you relate an example or story where you were able to question, experiment and explore issues in your organisation?

- In your experience how do people learn best? Alone/peers/group led by team leader?

- How typical it is of Singapore?

\section{How is decision making approached in your organisation?}

Prompts:

- Does your organisation have methods and mechanisms for involving people in keydecision making process?

- Do you feel free to discuss or disagree with other's views?

- If you have problems, how do you solve them in the organisation?

- How typical it is of Singapore?

\section{SINGAPORE AND ITS CULTURE}

\section{How would you describe the culture of} Singapore?

Prompts:

- Is there a 'Singapore Culture'?

- Do Singaporeans, in your experience, work well in teams?

- Are Singaporeans concerned about what other people think of them?

- We live in a rapidly changing world? How do Singaporeans cope with change?

7. Do you think the LO concept has been useful to you and your organisation? In what ways?

Prompts

- Does it work in your organisation? 
- How do people see the relationship between LO concept and creativity?

- How do people see the relationship with learning and the learning organisation concept?

\section{REFERENCES}

Argyris, C. (1999). On organisational learning. Malden, Mass: Blackwell Publishers.

Bartlett, C.A. \& Ghoshal, S. (1998). Managing across borders. London: Random House.

Brookfield, S.D. (1987). Developing critical thinkers. San Francisco: Jossey-Bass Publishers.

Cassell, C. \& Symon, G. (1994). Qualitative methods in organizational research: A practical guide. London: Sage Publication.

Constas, M.A. (1992). Qualitative analysis as a public event: The documentation of category development procedures. American Educational Research Journal, 29(2), 253266.

Craft, A. (2003). The limits to creativity in education: Dilemmas for the educator. British Journal of Educational Studies, 51(2), 113127.

Creswell, J. W. (1998). Qualitative inquiry and research design: Choosing among five traditions. Thousand Oaks, CA: Sage Publication.

Cropley, A. J. (1997). Fostering creativity in the classrooms: General principles. In M.A. Runco (Eds.), The creativity research handbook (Vol. 1, pp. 83-114). Cresskill, NJ: Hampton Press.

Crotty, M. (1998). The foundation of social research-meaning and perspective in the research process. Australia: Allen \& Unwin Pte Ltd.

Davenport, T.H., \& Prusak, L. (1997). Working knowledge: How organizations manage what they know. Boston, MA: Harvard Business School Press.

DeGeus, A.P. (1988). Planning as learning. Harvard Business Review, 2, 70-74.
Edmondson, A., \& Moingeon, B. (1996). When to learn how and when to learn why: Appropriate organisational learning processes as source of competitive advantage. In B. Moingeon \& A. Edmondson (Eds). Organisational learning and competitive advantage (pp. 17-37). London: Sage Publications.

Elena, A.P., Joep., C.P. \& Susanne, B. (2003). Metaphor and the dynamics of knowledge in organization studies: A case study of the learning organization. Paper presented at the $5^{\text {th }}$ International Organisational Learning and Knowledge Conference, 30 May -2 June, Management School, Lancaster University.

Epstein, M.J. \& Roy, M.J. (1997). Using ISO for improved organizational learning and environmental improvement. Environmental Quality Management. 17(1). 620-627.

Denzin, N. \& Lincoln, Y. S. (2003). Collecting and interpreting qualitative materials. Thousand Oaks, CA: Sage.

Dixon, N. (1998). The responsibilities of members in an organization that is learning. The Learning Organization, 5 (4), 1-8.

Finger, M., \& Brand, S.B. (2003). The concept of the "Learning Organization" applied to the transformation of the Public Sector: Conceptual contributions for theory development. In M. Easterby-Smith, J. Burgoyne \& L. Araujo (Eds). Organizational Learning and the Learning organization: Developments in theory and practice. UK: Sage Publications.

Fiol, M.C., \& Lyles, M.A. (1985). Organisational Learning. Academy of Management Review, 10(4), 803-813.

Fullan, M.G. (1993). Change forces: Probing the depths of educational reform. London: Falmer Press.

Gardiner, P. \& Whiting, P. (1997). Success factors in learning organizations: An empirical study. Industrial and Commercial Training, 29 (2), 41.

Gardner, H. (1985). The mind's new science. New York: Continum. 
Garratt, B. (1987). Learning is the core of organizational survival: Action learning is the key integrating process. Journal of Management Development, 6 (2), 34-44.

Goh, C. T. (1997). Shaping our future: Thinking schools and a learning nation. Speeches, 21(3), 12-20.

Grieves, J. (2000). Navigating change into the new millennium: Themes and issues for the learning organization. The Learning Organisation , 7 (2), 54-74.

Handy, C. (1995). Trust and the virtual organization. Harvard Business Review, 73(3), 40-50.

Harley, U. C. V. \& Low, L. (1998). Crafted culture: Governmental sculpting of modern Singapore and effects on business environments. Journal of Organizational Change Management, 11 (6), 53-554.

Isaacs, W. (1999). Dialogue and the art of thinking together. New York: Doubleday.

Jackson, B. (2001). Management Gurus and management fashions. London: Routledge.

Kiechel,W. (1990). The organization that learns. Fortune, 12, 133-136.

Manpower News (2000). The opening of the inaugural Singapore learning festival, (http:// www.gov.sg.lMOM).

Marquardt, M. J. (2002). Building the learning organization: Mastering the five elements for corporate learning. Palo Alto, CA: DaviesBlack Publishing.

Marquardt, M. \& Reynolds, A. (1994). Global learning organization: Gaining advantage through continuous learning. New York: Irwin.

Morgan, G. (1993). Imagination: The art of creative management, London: Sage Publications.

Negus, K., \& Pickering, M. (2004). Creativity, communication and cultural value. London: Sage Publications.

Ng, P.T. (2005) The learning school. Singapore: Prentice Hall.

Ng, P. T. (2004) GROW ME! Coaching for schools. Singapore: Prentice Hall.
Ochse, R. (1990). Before the gates of excellence: The determinants of creative genius. UK: Cambridge University Press.

Pedler, M. \& Aspinwall, K. (1998). A concise guide to the learning organization. New York: Doubleday Currency.

Piaget, J. (1972). Intellectual evolution from adolescence to adulthood. Human Development, 15, 1-12.

Pillai, R., Schriesheim, C. \& Williams, E. (1999). Fairness perceptions and trust as mediators for transformational and transactional leadership: A two-study sample. Journal of Management, 25(6), 897-933.

Senge, P. (1990). The fifth discipline: The art and practice of the learning organization. New York: Currency Doubleday.

Senge, P. (1990b). The leaders' new work: Building learning organisations. Sloan Management Review, 32(1), 7-23.

Senge, P., Kleiner, A., Roberts, C., Ross, R.B \& Smith, B.J. (1994). The fifth discipline fieldwork: Strategies and tools for building a learning organization. Great Britain: Nicholas Brealey Publishing.

Senge, P., Cambron-McCabe, N., Lucas, T., Smith, B., Dutton, J \& Kleiner, A. (2001). Schools that learn: A fifth discipline fieldbook for educators, parents, and everyone who cares about education. Great Britain: Nicholas Brealey Publishing.

Smith, E. M., Thorpe, R. \& Lowe, A. (1997). Management research: An introduction. London: Sage Publication.

Sternberg, R. J., \& Lubart, T. I. (1999) The concept of creativity: Prospects and paradigms In Sternberg, R. J (Eds.), Handbook of Creativity. New York: Cambridge University Press.

Stewart, D. (2001.) Reinterpreting the learning organisation. The Learning Organisation, 8 (2), 141-152.

Tan, A.G. (2001). Singaporean teachers' perception of activities useful for fostering creativity. Journal of Creative Behaviour, 35(2), 131-148. 
Tan, J., \& Gopinathan, S. (2000). Education reform in Singapore: Towards greater creativity and innovation. Singapore, National Institute for Research Advancement, Vol. 7(3), 1-6.

Vasil, R. (2000). Governing Singapore Democracy and national development. Singapore: South Wind Production.

Wang, L. C., \& Ahmed, P. K. (2003). Organisational learning: A critical review. The Learning Organisation, 19(1), 8-17.
Watkins, K.E., \& Marsick, V.J. (1994). Sculpting the learning organization. San Francisco: Jossey-Base.

Yeo, R. (2006) Implementing organisational learning initiatives: Insights from Singapore organisations. Development and Learning in Organisations, 20, 10-12.

Zepke, N., Nugent, D \& Leach, L. (2003) Reflection to transformation, A self-help book for teachers. New Zealand: Dunmore Press.

Zhang, Y. (1994). Leadership attributes in a cultural setting in Singapore. International Journal of Educational Management, 8 (6), 16-18. 